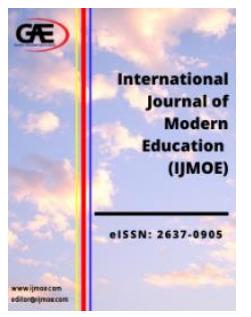

\author{
INTERNATIONAL JOURNAL OF \\ MODERN EDUCATION \\ (IJMOE) \\ www.ijmoe.com
}

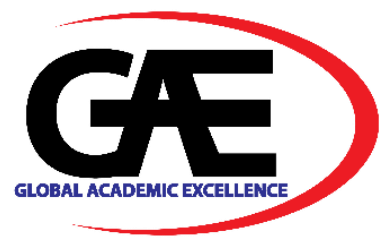

\title{
MENTAL HEALTH CONDITION OF INDONESIAN STUDENTS IN AMID PANDEMIC COVID-19, DO THEY NEED PROFESSIONAL HELP?
}

\author{
Dede Rahmat Hidayat ${ }^{*}$, Susi Fitri $^{2}$, Eka Wahyuni ${ }^{3}$
}

1 Department of Guidance and Counselling, Universitas Negeri Jakarta, Indonesia Email: dederhidayat@unj.ac.id

2 Department of Guidance and Counselling, Universitas Negeri Jakarta, Indonesia Email: susi.fitri@unj.ac.id

3 Department of Guidance and Counselling, Universitas Negeri Jakarta, Indonesia Email: e.wahyuni@unj.ac.id

* Corresponding Author

\section{Article Info:}

\section{Article history:}

Received date: 25.11 .2021

Revised date: 20.12 .2021

Accepted date: 27.12 .2021

Published date: 31.12 .2021

\section{To cite this document:}

Hidayat, D. R., Fitri, S. M., \& Wahyuni, E. (2021). Mental Health Condition Of Indonesian Students In Amid Pandemic Covid-19, Do They Need Professional Help?. International Journal of Modern Education, 3(11), 68-76.

DOI: $10.35631 /$ IJMOE.311005

This work is licensed under CC BY 4.0

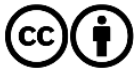

\begin{abstract}
:
The Covid-19 pandemic is not yet sure when it will end. The impact on education is the government's policy to implement monitored online/offline learning modes. For students this makes them feel uncertain, his study examined the mental health of Indonesian students in the Covid-19 pandemic situation. A number of students were recruited to become respondents using the snowball sampling technique. The researcher contacted the teachers at schools in Jakarta Indonesia. The teacher contacts students who are willing to fill out the instrument. collected 397 participants who are high school students. The instrument used was the Counselling Centre Assessment of Psychological Symptoms (CCAPS), Indonesia version They completed the CCAPSIndonesia along with several carefully selected scales. In CCAPS there are eight forms of mental health disorders that are assessed, namely depression, general anxiety, social anxiety, academic distress, eating concern, family distress, hostility and substance. The results have shown that in general students do not experience serious mental health disorders, the highest symptoms are social anxiety and academic stress. It seems that restrictions on social activities and ways of learning that have not been fixed have caused students in Jakarta to experience mental health problems, thus requiring professional help. In addition, there needs to be clarity regarding the learning mode that will be implemented.
\end{abstract}

Keywords:

CCAPS, High School Students, Indonesia, Mental Health, Covid-19 


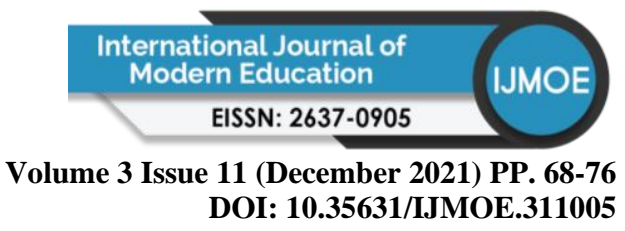

\section{Introduction}

The impact of the pandemic on health is not only physical, in the form of various complaints such as shortness of breath, loss of smell (Lee et al., 2020). But also various psychological complaints are reported to be experienced by many people, the emotional condition of students (Wenjun et al., 2020). The condition of the covid-19 pandemic is described by (Boer, 2021) as through a roller coaster of emotions, because when covid hit there was a policy of physical and social restrictions, resulting in the lack of interaction with colleagues and students, workrelated stress, dull, shifts in my work portfolio and need for adaptation. Mental health problems are important to identify because they have an impact on wider life, such as daily life, academic life and social life. Regarding these conditions, it is very necessary to have appropriate interventions to avoid problems that are not handled or even bigger. However, they are still developing in an important stage for learning.

Some research on the impact of Covid-19 on mental health for students shows that they are a vulnerable group to be affected by mental health disorders. Research conducted in Indonesia and several other countries show academic difficulties and feeling lonely (Kaligis et al., 2021).. The most prevalent mental health problem among students was anxiety (Arribathi et al., 2021, anxiety and depression (Halperin, Henderson, Prenner, \& Grauer, 2021) the exacerbation of existing anxieties and poses several new stressors that cumulatively may increase the risk of Non-suicidal self-injury (NSSI) (Hasking et al., 2021). The various research conducted generally focus on partial forms of mental health disorders. Whereas as is known mental health disorders have many forms and are related to certain life contexts. It is necessary to conduct research that seeks to reveal the various types of mental health experienced by students during this Covid-19 pandemic.

This study aims to comprehensively explore various forms of mental health disorders resulting from the COVID-19 pandemic. In this study, the Counselling Centre Assessment of Psychological Symptoms (CCAPS) instrument was used to diagnose eight forms of mental health (Locke et al., 2011), namely (D), General Anxiety (GA), Social Anxiety. (SA), Academic Distress (DA), Eating Concern (EC), Family Distress (FD), Hostility (H), and Drug/Cigarette/Substance Use (S). The findings of this study form the basis for a psychological intervention program that will be developed to prevent wider and more severe problems. Early psychological interventions may be beneficial for the vulnerable groups of healthcare workers with the presence of physical symptoms, prior medical conditions and those who are not medically trained (Chew et al., 2020).

\section{Literature Review}

\section{Mental Health Condition On Indonesian Student}

In Indonesia, no data are available about mental health problems and the needs of transitionalage youth.(Kaligis et al., 2021) This was a cross-sectional study involving 393 Indonesians aged 16-24 years in May 2020. More than 90\% of students had financial and academic difficulties and felt lonely. The most prevalent mental health problem among students was anxiety (95.4). Students' anxiety regarding the use of the online learning mode during the COVID-19 pandemic is related to three factors: offline interactions on campus, learning motivations, and the shift in the learning mode (Arribathi et al., 2021). 


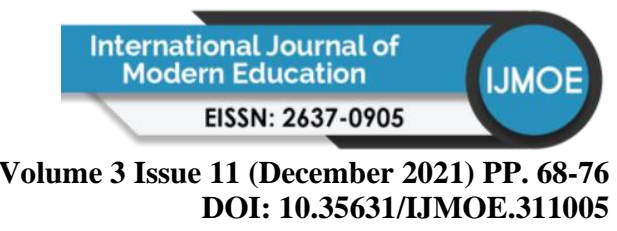

In Philippine Though there was increased anxiety felt by students regarding getting the COVID-19 infection, there is still enough evidence that students among two local colleges in Southern Philippines practice measures to deal with anxiety during this threat of global health security (Baloran, 2020).

\section{The Counselling Centre Assessment of Psychological Symptoms (CCAPS)}

CCAPS Originally developed by the staff at the University of Michigan counselling centre in 2001, to assess the psychological symptoms of college students; the CCAPS-62. The CCAPS62, was designed to assess key domains of college student's mental health concerns (CCMH, 2012a, 2014; Locke et al., 2011). The eight subscales of the CCAPS-62 include Depression, Generalized Anxiety, Social Anxiety, Academic Distress, Eating Concerns, Family Distress, Hostility, and Substance Abuse. In addition, it includes an overall Distress Index that provides a quick assessment of the respondent's general psychological distress.

Since its development, several empirical studies have been conducted with consistent findings supporting the CCAPS-62's psychometric properties and clinical applications to the college student population (Locke et al., 2011; Michelle \& Duszak, 2014; McAleavey et al., 2012; Ratanasiripong et al., 2015). Due to its specificity for college students, its strong psychometric properties, and its availability for free use by college counselling centres, the CCAPS-62 has the potential as an instrument to measure psychological distress in Indonesian college students.

To this end, an Indonesian translation that is psychometrically sound and culturally valid would need to be developed. Before selecting the CCAPS-62 as the instrument for Indonesian translation and validation, each item on the CCAPS-62 was critically evaluated to ensure appropriate usage in the Indonesian cultural context. In addition, the eight subscales of the CCAPS-62 resemble psychological issues that Indonesia High school students. No other instrument is as comprehensive or provides a multidimensional measurement that encompasses these eight important areas.

\section{Method}

\section{Participants}

The participants in this study were students in Jakarta, they were recruited using the snowball technique. The procedure is that the researcher contacted the teachers who were the contact persons. Then the teachers contacted student representatives, students who were willing to be respondents. Previously they were asked to fill out a consent form to ensure volunteering. The number of all respondents is 397 people aged 14-17 they are higher school students in Jakarta.

\section{Instruments}

The research instrument used is the CCAPS Indonesia version which consists of 60 items, the aspects assessed are 8 aspects, namely Depression (D), General Anxiety (GA), Social Anxiety (SA), Academic Distress (DA), Eating Disorders/Eating Concern (EC), Family Distress (FD), Hostility $(\mathrm{H})$, and Use of Drugs/Cigarettes/Substances (S). The original version is sixty-two items but after adaptation for Indonesian respondents there was a change from 62 to 60 regarding subscale substance previously there was content about the alcoholic addict, due Indonesian people majority are Muslim, so they are not alcoholic consume but smoke consume, so there was the switch from alcohol to smoking but the consequences are the elimination of 
Volume 3 Issue 11 (December 2021) PP. 68-76 DOI: 10.35631/IJMOE.311005

amount of item. Instruments are given in their form and sent via the WA application. So they can download the questionnaire.

\section{Research Procedure}

The research questionnaire that will be given is made in google form format. Researchers distributed questionnaires through the WhatsApp application to teachers who were research partners, then partner teachers continued sending the questionnaires to their fellow teachers. Filled out questionnaires will be analyzed while incomplete questionnaires will not be analyzed.

\section{Data Analysis}

Data which has been collected analyzed by descriptive and categorizing and also intercorrelation between subscales, all of which were processed using SPSS 26 version

\section{Result and Discussion}

\section{Descriptive}

The Counseling Center Assessment of Psychological Symptoms (CCAPS) questionnaire consists of eight subscales, namely Depression (D), General Anxiety (GA), Social Anxiety (SA), Academic Distress (DA), Eating Concern (EC), Family Distress (FD), Hostility (H), and Use of Drugs/Cigarettes/Substance (S).

CCAPS questionnaires were given to high school students. A total of 397 students participated in filling out the questionnaire, with details of 130 students in tenth class, 113 students in eleventh class, and 154 students in twelfth class. The descriptive analysis of the CCAPS questionnaire is presented in Table 1.

Table 1. Descriptive Analysis of CCAPS

\begin{tabular}{|c|c|c|c|c|c|c|c|c|c|}
\hline & D & GA & SA & DA & EC & FD & H & $\mathbf{S}$ & TOTAL \\
\hline $\mathrm{N}$ & 397 & 397 & 397 & 397 & 397 & 397 & 397 & 397 & 397 \\
\hline Mean & 9.8212 & 12.8967 & 14.0378 & 8.6725 & 12.3879 & 9.3275 & 11.9169 & 1.0151 & 90.0756 \\
\hline Median & 9.00 & 12.0000 & 14.00 & 9.0000 & 12.0000 & 10.0000 & 1.0 & .0000 & 9.0000 \\
\hline Mode & 19.0 & 9.00 & 1. & 10.00 & 10. & 12.00 & 5.00 & .00 & 56.00 \\
\hline Std. Des & 9.95778 & 8.43405 & 4.98645 & 3.63465 & 5.67385 & 5.09491 & 7.09607 & 2.22129 & 34.74546 \\
\hline Range & 50.00 & 36.00 & 28.00 & 20.00 & 36.00 & 24.00 & 28.00 & 16.00 & 213.00 \\
\hline Minim & .00 & .00 & .00 & .00 & .00 & .00 & .00 & .00 & .00 \\
\hline Maxir & 50.00 & 36.00 & 28.00 & 20.00 & 36.00 & 24.00 & 28.00 & 16.00 & 213.00 \\
\hline Sum & 7869.00 & 5120.00 & 5573.00 & 3443.00 & 4918.00 & 3703.00 & 4731.00 & 403.00 & 35760.00 \\
\hline
\end{tabular}

Table 1 shows that the standard deviation of each CCAPS instrument subscale is relatively low. A low standard deviation value indicates that respondents generally have a uniform level of symptoms in each psychological symptom subscale. The overall graph of the distribution of the CCAPS instrument results for respondents can be seen in the P-P plot in Figure 1. 


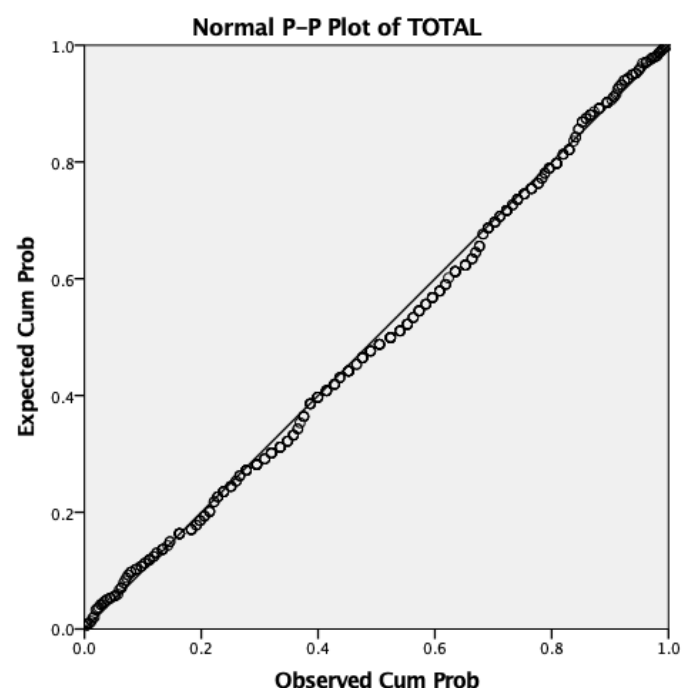

Figure 1. P-P Plot Total Result of Mental Health Respondents

Figure 1 shows the P-P Plot graph of the total score of the CCAPS instrument. The distribution of the total score obtained looks uniform and is on a normal curve. In the P-P Plot graph, it can be seen that the tendency of the results of measuring psychological symptoms in high school students in Jakarta students is uniform, there are no data that are extreme or different from one another. The results of the CCAPS questionnaire categorization for tenth class students are listed in Table 2.

Table 2. Leveling Mental Health Condition for Tenth Class

\begin{tabular}{|l|c|c|c|r|r|r|r|r|r|}
\hline \multicolumn{1}{|c|}{ Level } & D & GA & SA & DA & EC & FD & H & S & TOTAL \\
\hline Low & $40 \%$ & $51 \%$ & $17 \%$ & $35 \%$ & $57 \%$ & $67 \%$ & $41 \%$ & $98 \%$ & $46 \%$ \\
\hline Middle & $49 \%$ & $36 \%$ & $58 \%$ & $62 \%$ & $40 \%$ & $29 \%$ & $38 \%$ & $2 \%$ & $50 \%$ \\
\hline High & $11 \%$ & $13 \%$ & $25 \%$ & $4 \%$ & $3 \%$ & $4 \%$ & $22 \%$ & $1 \%$ & $4 \%$ \\
\hline Total & $100 \%$ & $100 \%$ & $100 \%$ & $100 \%$ & $100 \%$ & $100 \%$ & $100 \%$ & $100 \%$ & $100 \%$ \\
\hline
\end{tabular}

Based on Table 2, it can be seen that on the subscale of depression, social anxiety, and academic distress in class $X$ students with the largest percentage are at the moderate level, each $\mathrm{D}=49 \%$; $\mathrm{SA}=58 \%$; $\mathrm{DA}=62 \%$. While the subscales of general anxiety, eating disorders, family distress, hostility, and use of drugs/cigarettes were at a low level, with each percentage $\mathrm{GA}=51 \%$; $\mathrm{EC}=57 \% ; \mathrm{FD}=67 \% ; \mathrm{H}=41 \% ; \mathrm{S}=98 \%$. Table 2 generally shows the level of psychological symptoms of tenth class students as much as $50 \%$ in the moderate level, followed by $46 \%$ in the low level, and $4 \%$ in the high level. Furthermore, the results of the CCAPS questionnaire categorization for eleventh class students are listed in Table 3.

Table 3. Leveling Mental Health Condition for Eleventh Class

\begin{tabular}{|l|r|r|r|r|r|r|r|r|r|}
\hline \multicolumn{1}{|c|}{ Level } & D & GA & SA & DA & EC & FD & H & S & TOTAL \\
\hline Low & $56 \%$ & $57 \%$ & $25 \%$ & $46 \%$ & $50 \%$ & $69 \%$ & $44 \%$ & $94 \%$ & $51 \%$ \\
\hline Middle & $41 \%$ & $32 \%$ & $64 \%$ & $54 \%$ & $47 \%$ & $31 \%$ & $38 \%$ & $4 \%$ & $48 \%$ \\
\hline High & $4 \%$ & $12 \%$ & $12 \%$ & $0 \%$ & $3 \%$ & $0 \%$ & $18 \%$ & $2 \%$ & $1 \%$ \\
\hline Total & $100 \%$ & $100 \%$ & $100 \%$ & $100 \%$ & $100 \%$ & $100 \%$ & $100 \%$ & $100 \%$ & $100 \%$ \\
\hline
\end{tabular}


Volume 3 Issue 11 (December 2021) PP. 68-76 DOI: 10.35631/IJMOE.311005

The level of psychological symptoms in eleventh class students as stated in Table 3 shows that on the subscale social anxiety and academic distress have the largest percentage and are at a moderate level. Each percentage is $\mathrm{SA}=64 \%$; $\mathrm{DA}=54 \%$. While the subscales of depression, general anxiety, eating disorders, family distress, hostility, and use of drugs/cigarettes were at a low level, each with a percentage of $\mathrm{D}=46 \%$; $\mathrm{GA}=57 \%$; $\mathrm{EC}=50 \% ; \mathrm{FD}=69 \% ; \mathrm{H}=44 \%$; $\mathrm{S}=94 \%$. In contrast to tenth class students, eleventh class students in Table 3 generally show the level of psychological symptoms in the low level with a percentage of $51 \%$, followed by $48 \%$ in the moderate level, and $1 \%$ in the high level. The results of the CCAPS questionnaire categorization for twelfth class students are listed in Table 4.

Table 4. Leveling Mental Health Condition for Twelfth Class

\begin{tabular}{|l|r|r|r|r|r|r|r|r|r|}
\hline \multicolumn{1}{|c|}{ Level } & D & \multicolumn{1}{c|}{ GA } & SA & \multicolumn{1}{c|}{ DA } & \multicolumn{1}{c|}{ EC } & \multicolumn{1}{c|}{ FD } & H & \multicolumn{1}{c|}{ S } & TOTAL \\
\hline Low & $36 \%$ & $55 \%$ & $10 \%$ & $2 \%$ & $54 \%$ & $4 \%$ & $40 \%$ & $92 \%$ & $25 \%$ \\
\hline Middle & $53 \%$ & $38 \%$ & $73 \%$ & $82 \%$ & $45 \%$ & $84 \%$ & $43 \%$ & $7 \%$ & $73 \%$ \\
\hline High & $12 \%$ & $8 \%$ & $16 \%$ & $16 \%$ & $1 \%$ & $12 \%$ & $18 \%$ & $1 \%$ & $3 \%$ \\
\hline Total & $100 \%$ & $100 \%$ & $100 \%$ & $100 \%$ & $100 \%$ & $100 \%$ & $100 \%$ & $100 \%$ & $100 \%$ \\
\hline
\end{tabular}

Table 4, it can be seen that on the depression, social anxiety, academic distress, family distress, and hostility subscales in twelfth class students with the largest percentage are at the moderate level, each with a percentage of $\mathrm{D}=53 \%$; $\mathrm{SA}=73 \%$; $\mathrm{DA}=82 \% ; \mathrm{FD}=84 \% \mathrm{H}=43 \%$. Meanwhile, the general anxiety, eating disorders, and drug/smoking use subscales were at a low level, each with a percentage of $\mathrm{GA}=55 \%$; $\mathrm{EC}=54 \% ; \mathrm{S}=92 \%$. Table 4 generally shows the level of psychological symptoms of twelfth class students as much as $73 \%$ in the moderate level, followed by $25 \%$ in the low level, and $3 \%$ in the high level. The results of the CCAPS questionnaire levelling for all students of high school students in Jakarta are listed in Table 5.

Table 5. Leveling Mental Health Condition for All Class

\begin{tabular}{|l|r|r|r|r|r|r|r|r|r|}
\hline \multicolumn{1}{|c|}{ Level } & \multicolumn{1}{c|}{ D } & GA & SA & DA & EC & FD & H & \multicolumn{1}{c|}{ S } & TOTAL \\
\hline Low & $43 \%$ & $54 \%$ & $17 \%$ & $25 \%$ & $54 \%$ & $43 \%$ & $41 \%$ & $94 \%$ & $39 \%$ \\
\hline Middle & $48 \%$ & $36 \%$ & $65 \%$ & $68 \%$ & $44 \%$ & $51 \%$ & $40 \%$ & $5 \%$ & $58 \%$ \\
\hline High & $9 \%$ & $11 \%$ & $18 \%$ & $7 \%$ & $2 \%$ & $6 \%$ & $19 \%$ & $1 \%$ & $3 \%$ \\
\hline Total & $100 \%$ & $100 \%$ & $100 \%$ & $100 \%$ & $100 \%$ & $100 \%$ & $100 \%$ & $100 \%$ & $100 \%$ \\
\hline
\end{tabular}

Table 5 shows that in general the percentages of depression, social anxiety, academic distress, and family distress subscales for high school students in Jakarta students are at a moderate level, each with a percentage of $\mathrm{D}=48 \% ; \mathrm{SA}=65 \%$; $\mathrm{DA}=68 \% ; \mathrm{FD}=51 \%$. Meanwhile, the subscales of general anxiety, eating disorders, hostility, and the use of drugs/cigarettes were at a low level, with each percentage $\mathrm{GA}=54 \% ; \mathrm{EC}=54 \% ; \mathrm{H}=41 \% ; \mathrm{S}=94 \%$. Table 5 as a whole shows the level of psychological symptoms of high school students in Jakarta as much as 58\% in the moderate level, followed by $39 \%$ in the low level and $3 \%$ in the high level..

\section{Correlation Between Subscale Of CCAPS}

Correlation between CCAPS subscales shows the relationship between one psychological symptom with another psychological symptom. The relationship between these symptoms can be seen from the correlation matrix in Table 6 below. 
Volume 3 Issue 11 (December 2021) PP. 68-76 DOI: 10.35631/IJMOE.311005

Table 6. Matrix Correlation Between Subscale of CCAPS

\begin{tabular}{|c|c|c|c|c|c|c|c|c|}
\hline & D & GA & SA & DA & EC & FD & H & S \\
\hline D & 1.000 & & & & & & & \\
\hline GA & 0.836 & 1.000 & & & & & & \\
\hline SA & 0.703 & 0.718 & 1.000 & & & & & \\
\hline DA & 0.695 & 0.624 & 0.583 & 1.000 & & & & \\
\hline EC & 0.461 & 0.438 & 0.339 & 0.397 & 1.000 & & & \\
\hline FD & 0.810 & 0.714 & 0.596 & 0.612 & 0.306 & 1.000 & & \\
\hline H & 0.619 & 0.632 & 0.578 & 0.527 & 0.330 & 0.618 & 1.000 & \\
\hline S & 0.331 & 0.408 & 0.208 & 0.247 & 0.052 & 0.434 & 0.242 & 1.000 \\
\hline
\end{tabular}

D (Depressi); GA (General Anxiety); SA (Social Anxiety); DA (Academic Distress); EC (Eating Concern); FD (Familiy Distress); H (Hostility); S (Substance)

In Table 6 it can be seen that the relationship between the CCAPS subscales on average is above 0.5 , except for the eating disorders (EC) and drug/cigarette use (S) subscales. The relationship between the EC subscale and all other subscales is below 0.5, as well as the relationship between $S$ and other CCAPS subscales. This shows that eating disorders and drug/smoking use do not have a strong correlation with the subscales of the CCAPS construct. The same thing was revealed by research conducted by Nordberg, Hayes, McAleavey, Castonguay, \& Locke (2013; Nordberg et al., (2018) which stated that eating concern and substances did not independently predict treatment needs.

In contrast to the EC and S subscales, the other subscales have medium and high correlation values, indicated by correlation values above 0.5 . The highest correlation value between subscales is shown by the GA and D subscales with a value of 0.836 . This shows that there is a relationship between depression and general anxiety

Students in Indonesia during the pandemic showed severe mental health disorders, of the 8 types of mental health disorders identified they were at a moderate level and some were even low. This result is actually beyond expectations because several surveys conducted show that students are a vulnerable group affected by COVID (Jung et al., 2021; Kaligis et al., 2021;Sujarwoto, Saputri, \& Yumarni, 2021).

The ability to overcome difficulties and problems as a result of covid-19 seems to be related to the resilience abilities of students (Karaar \& Canli, 2020) and good coping abilities because Positive emotion-focused coping strategies may be effective for reducing psychological symptoms (Gurvich et al., 2021). Those who have the right coping skills will generally have better health

\section{Conclusion}

The Covid-19 outbreak has shown a sloping trend and looks like it will soon be resolved, however, the impact is still wide and needs to be handled with care. Because it has unpredictable characteristics so that ups and downs can still be seen. This condition will give cause uncertainty. This uncertainty will lead to confusion and uncertainty over what to do and of course, have an impact on mental health. In the context of education, those affected are not only the teachers but also students who are the direct perpetrators of education. Based on CCAPS, it can be seen that some students experience mental health disorders, although in 


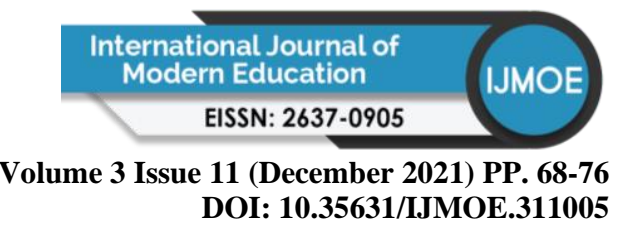

varying levels, but in general they are not in a worrying condition, so not many need professional help to overcome mental health disorders, because they are generally at moderate and mild levels. This condition is suspected by the students' coping abilities in dealing with psychological stress due to its various effects.

\section{Acknowledgment}

This research was funded by Research scheme from Universitas Negeri Jakarta contract number 316/UN39/KU.OO.O1/202 1 and agreement contract number: 141/KI/LPPM/IV/2021thank you for assisting to our dean and student who has participate on this research.

\section{References}

Arribathi, A. H., Rosyad, A. M., Budiarto, M., Supriyanti, D., Arribathi, A. H., \& Rosyad, A. M. (2021). An Analysis of Student Learning Anxiety During the COVID-19 Pandemic : A Study in Higher Education An Analysis of Student Learning Anxiety During the COVID-19 Pandemic : A Study in Higher Education. The Journal of Continuing Higher Education, O(0), 1-14. https://doi.org/10.1080/07377363.2020.1847971

Baloran, E. T. (2020). Knowledge , Attitudes , Anxiety, and Coping Strategies of Students during COVID-19 Pandemic. Journal of Loss and Trauma, O(0), 1-8. https://doi.org/10.1080/15325024.2020.1769300

Boer, H. De. (2021). Studies in Higher Education COVID-19 in Dutch higher education COVID-19 in Dutch higher education. https://doi.org/10.1080/03075079.2020.1859684

Chew, N. W. S., Ngiam, J. N., Tan, B. Y.-Q., Tham, S.-M., Tan, C. Y.-S., Jing, M., ... Sharma, V. K. (2020). Asian-Pacific perspective on the psychological well-being of healthcare workers during the evolution of the COVID-19 pandemic. BJPsych Open, 6(6), 1-11. https://doi.org/10.1192/bjo.2020.98

Gurvich, C., Thomas, N., Thomas, E. H. X., Hudaib, A. R., Sood, L., Fabiatos, K., ... Kulkarni, J. (2021). Coping styles and mental health in response to societal changes during the COVID-19 pandemic. International Journal of Social Psychiatry, 67(5), 540-549. https://doi.org/10.1177/0020764020961790

Halperin, S. J., Henderson, M. N., Prenner, S., \& Grauer, J. N. (2021). Prevalence of Anxiety and Depression Among Medical Students During the Covid-19 Pandemic: A CrossSectional Study. Journal of Medical Education and Curricular Development, 8, 238212052199115. https://doi.org/10.1177/2382120521991150

Hasking, P., Lewis, S. P., Bloom, E., Brausch, A., Kaess, M., \& Robinson, K. (2021). Impact of the COVID-19 pandemic on students at elevated risk of self-injury: The importance of virtual and online resources. School Psychology International, 42(1), 57-78. https://doi.org/10.1177/0143034320974414

Jung, J., Horta, H., Postiglione, G. A., Jung, J., Horta, H., \& Postiglione, G. A. (2021). Studies in Higher Education Living in uncertainty: the COVID-19 pandemic and higher education in Hong Kong Living in uncertainty: the COVID-19 pandemic and higher education in Hong Kong. https://doi.org/10.1080/03075079.2020.1859685

Kaligis, F., Ismail, R. I., Wiguna, T., Prasetyo, S., Indriatmi, W., Gunardi, H., ... Magdalena, C. C. (2021). Mental health problems and needs among transitional-age youth in Indonesia. International Journal of Environmental Research and Public Health, 18(8). https://doi.org/10.3390/ijerph18084046 
Volume 3 Issue 11 (December 2021) PP. 68-76 DOI: 10.35631/IJMOE.311005

Karaar, B., \& Canli, D. (2020). Psychological resilience and depression during the COVID-19 pandemic in Turkey. Psychiatria Danubina, 32(2), 273-279. https://doi.org/10.24869/PSYD.2020.273

Lee, D. J., Lockwood, J., Das, P., Wang, R., Grinspun, E., \& Lee, J. M. (2020). Self-reported anosmia and dysgeusia as key symptoms of coronavirus disease 2019. Canadian Journal of Emergency Medicine, 22(5), 595-602. https://doi.org/10.1017/cem.2020.420

Locke, B. D., Buzolitz, J. S., Lei, P. W., Boswell, J. F., McAleavey, A. A., Sevig, T. D., ... Hayes, J. A. (2011). Development of the Counseling Center Assessment of Psychological Symptoms-62 (CCAPS-62). Journal of Counseling Psychology, 58(1), 97-109. https://doi.org/10.1037/a0021282

McAleavey, A. A., Nordberg, S. S., Hayes, J. A., Castonguay, L. G., Locke, B. D., \& Lockard, A. J. (2012). Clinical validity of the counseling center assessment of psychological symptoms-62 (CCAPS-62): Further evaluation and clinical applications. Journal of Counseling Psychology, 59(4), 575-590. https://doi.org/10.1037/a0029855

Michelle, E., \& Duszak, P. (2014). Evaluating the Effectiveness of Counseling Center-Based Psychotherapy Outcome Measures: a Statistical Comparison of the Counseling Center Assessment of Psychological Symptoms and the Outcome Questionnaire, (August). Retrieved from https://collections.lib.utah.edu/dl_files/74/f9/74f9c50a1fce962f97df2ec471ecd5ccad8 50673.pdf

Ratanasiripong, P., Wang, C. dc, Ratanasiripong, N., Hayes, J. A., Kaewboonchoo, O., \& Kathalae, D. (2015). Development and Cross-Cultural Validation of the Counseling Center Assessment of Psychological Symptoms-Thai Version. The Counseling Psychologist, 43(2), 248-271. https://doi.org/10.1177/0011000014566991

Sujarwoto, Saputri, R. A. M., \& Yumarni, T. (2021). Social Media Addiction and Mental Health Among University Students During the COVID-19 Pandemic in Indonesia. International Journal of Mental Health and Addiction. https://doi.org/10.1007/s11469021-00582-3

Wenjun, C., Ziwei, F., Guoqiang, H., Mei, H., Xinrong, X., Jiaxin, D., \& Jianzhong, Z. (2020). The psychological impact of the COVID-19 epidemic on college students in China. Psychiatry Research, 287(March 20, 2020), 1-5. Retrieved from $\mathrm{http}: / / \mathrm{www} . \mathrm{embase} . \mathrm{com} / \mathrm{search} /$ results?subaction=viewrecord $\&$ from=export\&id=L20 05406993\%0Ahttp://dx.doi.org/10.1016/j.psychres.2020.112934 